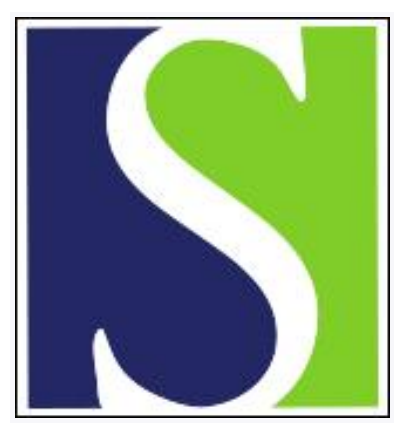

Scand J Work Environ Health 1997;23(2):104-113

https://doi.org/10.5271/sjweh.187

Issue date: Apr 1997

A meta-analysis of epidemiologic studies of lung cancer in welders

by Moulin JJ

The following articles refer to this text: 2002;28(3):163-167;

2004;30(3):206-214; 2007;33(5):379-386; 2008;34(6):444-450

Key terms: meta-analysis; stainless steel; welding

This article in PubMed: www.ncbi.nlm.nih.gov/pubmed/9167233

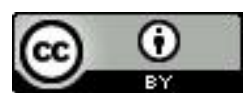




\title{
A meta-analysis of epidemiologic studies of lung cancer in welders
}

\author{
by Jean Jacques Moulin, MD'
}

\begin{abstract}
Moulin JJ. A meta-analysis of epidemiologic studies of lung cancer in welders. Scand $J$ Work Environ Health $1997 ; 23(2): 104-13$.
\end{abstract}

\begin{abstract}
Objective A meta-analysis of epidemiologic studies was carried out on lung cancer risk among shipyard, mild steel, and stainless steel welders, and the role of asbestos exposure and smoking was considered.

Methods The meta-analysis consisted of calculating combined relative risks (RR) and their variances through a logarithm transformation of published RR values and a weighing using the inverted variance of each RR.

Results The literature provided 18 case-referent and 31 cohort studies. The combined RR values were 1.38 [observed 1028, 95\% confidence interval $(95 \%$ CI) 1.29-1.48] for "all or unspecified welding categories", 1.30 (observed 305, 95\% CI 1.14-1.48) for shipyard welders, and 1.35 (observed 173, 95\% CI 1.15-1.58) for nonshipyard welders. Similar combined RR values (RR) were observed for mild steel welders (combined RR 1.50 , observed $137,95 \% \mathrm{CI} 1.18-1.91$ ) and stainless steel welders (combined RR 1.50 observed $114,95 \% \mathrm{CI}$ $1.10-2.05$ ). No significant heterogeneity was discerned between studies of any welding or study design category. A marked healthy worker effect may also lead to an underestimation of the standardized mortality ratio for lung cancer among stainless steel welders. Furthermore, welders of any category are likely to be exposed to asbestos. Welders also seem to smoke more than the general male population, and therefore the hypothesis of tobacco overconsumption among welders could not be discarded.

Conclusions A $30-40 \%$ increase in the RR of lung cancer among welders cannot be explained by hexavalent chromium and nickel exposure among stainless steel welders. The combination of the carcinogenic effects of asbestos exposure and smoking may account for part of the lung cancer excess observed.
\end{abstract}

Key terms meta-analysis, stainless steel, welding.

The risk of lung cancer in welders is an important issue in occupational epidemiology since (i) there may be as many as 3 million workers engaged in welding in industrialized countries (1) and (ii) welders may have been exposed to carcinogens according to welding activities, in particular exposure to hexavalent chromium and nickel when stainless steel is welded $(1,2)$. In addition, asbestos exposure is likely to have occurred in shipyards (2) and in other factories where welding is done (3).

Following the multicentric European study, carried out by the International Agency for Research on Cancer (IARC), on the lung cancer risk of stainless steel welders as compared with that of mild steel welders (1), the question of whether stainless steel welders are at higher lung cancer risk than mild steel welders has been recently debated in the literature. The reviews by Langård (4, 5 ) and the meta-analysis of 5 epidemiologic studies by Sjögren (6) suggested a specific relationship between lung cancer and exposure to hexavalent chromium and nickel when stainless steel is welded. Other authors have, however, disagreed with this proposal $(7,8)$.
This paper is a meta-analysis of epidemiologic studies aimed at assessing the relationship between lung cancer and welding activities (ie, shipyard versus nonshipyard welding and stainless steel versus mild steel welding). In addition, this assessment takes into account the role of asbestos exposure and smoking as possible confounding factors.

\section{Material and methods}

Published studies providing results on lung cancer risk in welders were selected for the meta-analysis (ie, casereferent studies focused on occupational lung cancer risks and cohort studies among welders followed for mortality or cancer incidence). All the studies published between 1954 and 1994 were selected. If more than 1 paper was written reporting the same study, or if a cohort study was included in another larger study published later, only 1 paper was included in the meta-analysis. Furthermore,

1 Institut National de Recherche et de Sécurité (INRS) (French National Institute for Research and Safety) Service d'Epidemiologie (Department of Epidemiology), Vandoeuvre Les Nancy, France.

Reprint requests to: Dr JJ Moulin, Institut National de Recherche et de Sécurité (INRS), Service d'Epidemiologie BP 27, 54501 Vandoeuvre Les Nancy, France. 
some studies were excluded from the meta-analysis for other reasons: (i) cohort updates for which only the updated results were included in the meta-analysis, (ii) cohorts followed for mortality and morbidity for which only the mortality results were included in the metaanalysis, and (iii) cohorts for which the results did not provide information required by the meta-analysis.

In order to investigate risks related to specific welding processes and welding fume components, the following 5 welding categories were defined: (i) "all or unspecified welding categories", including studies providing results for "welders" as a whole, without taking into account welding processes, most of them being populationbased studies and studies including subcohorts of all welding categories and providing a relative risk for all subcohorts combined; (ii) shipyard welding, including studies providing results for cohorts, or subcohorts, of shipyard welders; (iii) nonshipyard welding, including studies providing results for cohorts, or subcohorts, of welders never employed in shipyards and for which the status of mild steel or stainless steel welding was unknown; (iv) mild steel welding, including cohorts of nonshipyard welders never employed in stainless steel welding; and (v) stainless steel welding including cohorts of nonshipyard welders having been employed in stainless steel welding. Studies of the literature were included in these welding categories according to descriptions given in the study designs.

The relative risks (RR) were odds ratios (OR) for case-referent studies, standardized mortality ratios (SMR) for cohort studies, proportionate mortality ratios (PMR) for mortality studies and standardized incidence ratios (SIR) for cancer incidence studies. The observed numbers of cases, the relative risks, and their $95 \%$ confidence intervals $(95 \% \mathrm{CI})$ obtained for welding categories were extracted from the published papers.

Due to the fact that the study reports frequently failed to give the variance of the relative risks, the estimated variance (var) of each relative risk was calculated from the $95 \%$ confidence interval on the assumption that the log-transformed relative risks followed a Gaussian distribution $(9,10)$ :

$$
\operatorname{var}(\ln R R)=\left[\frac{\ln R R_{\text {upper }}-\ln R R_{\text {lower }}}{2 \times 1.96}\right]^{2} .
$$

The logarithms of the combined relative risks were computed as an average of the logarithmic transformation of the $\mathrm{RR}_{\mathrm{i}}$ values observed in each study, weighted by their inverted variance $w_{i}\left(w_{i}=1 /\right.$ var $)$ :

$$
\ln R R=\Sigma w_{i} \ln R R_{i} / \Sigma w_{i}
$$

The variance of combined relative risks were taken as $\operatorname{var}(\ln R R)=1 / \Sigma w_{i}$. The $95 \%$ confidence interval of the combined relative risks were calculated on the assumption of a log normal distribution:

$$
\ln R R=\ln R R \pm 1.96 \sqrt{\operatorname{var}(\ln R R)} .
$$

The chi-squared test for the heterogeneity of the RR values proposed by Greenland (10) was applied:

$$
\chi^{2}=\Sigma w_{i}\left(\ln R R_{i}-\ln R R\right)^{2} .
$$

The combined relative risks were calculated separately for the population-based studies, case-referent studies, and cohort studies and for all the studies combined since the method allows studies of different design, such as case-referent and cohort studies, to be combined (9).

Dose-response relationship was not addressed in the meta-analysis since, depending on the studies, the $R R_{i}$ values for graded welding exposure were either lacking or given in terms of different surrogates.

\section{Results}

\section{Studies included in the meta-analysis}

The literature provided 49 epidemiologic, 18 case-referent $(11-28)$, and 31 cohort $(29-59)$ studies that reported lung cancer risks for welders. Among them, 4 case-referent studies using odds ratios $(13,15,16,27)$ and 6 cohort studies using standardized mortality ratios or proportionate mortality ratios $(30,31,33,37,43,44)$ were population-based studies. These population-based studies were analyzed separately. The European cohort study carried out by IARC is noteworthy because of the size of the study population (11 092 welders) and because a specific job-exposure matrix was developed (55).

The following 13 studies were excluded from the meta-analysis (the reasons for exclusion being listed in table 1): 4 cohort studies carried out in Sweden (51), Finland (52), Germany (57) and France (58), whose results are included in the European study (55); the Danish case-referent study (27), which was nested in a cohort included in the European study (55); 6 cohort studies carried out in the United States $(31,36)$, Italy (34), Sweden $(38,41)$ and Germany $(46)$, which were updated later $(39,43,48,50,51,57) ; 1$ Swedish cancer incidence study (50), which was conducted in the same population as a mortality study (49); the study by Decoufle (13) because of its lack of confidence intervals.

The final number of studies contributing to the metaanalysis was 36 . The description of these investigations is given in table 2 . Some of those which provided results for more than 1 welding category may have contributed to several welding categories. Thirty-five studies were included in the meta-analysis, leading to 49 relative risks being extracted from the published papers. Most of the relative risks [ie, 35 of them $(71 \%)$ ] ranged between 0.99 and 2.00. Only 2 studies (4\%) provided relative risks lower than unity: odds ratios of 0.7 and 0.9 for shipyard 
Table 1. Studies of the literature and studies included in the meta-analysis on lung cancer in welders.

\begin{tabular}{|c|c|c|}
\hline & Included & Reason for exclusion \\
\hline \multicolumn{3}{|l|}{ Case-referent studies } \\
\hline Breslow et al, 1954, United States (11) & Yes & \\
\hline Blot et al, 1978, United States (12) & Yes & \\
\hline Decoufle et al, 1978 , United States (13) & No & $95 \%$ confidence intervals not provided \\
\hline Blot et al, 1980 , United States (14) & Yes & \\
\hline Gottlieb, 1980, United States (15) & Yes & \\
\hline Milne et al, 1983, United States (16) & Yes & \\
\hline Gerin et al, 1984, Canada (17) & Yes & \\
\hline Buiatti et al, 1985 , Italy (18) & Yes & \\
\hline Kjuus et al, 1986 , Norway (19) & Yes & \\
\hline Schoenberg et al, 1987, United States (20) & Yes & \\
\hline Lerchen et al, 1987, United States (21) & Yes & \\
\hline Benhamou et al, 1988 , France (22) & Yes & \\
\hline Rinsky et al, 1988, United States (23) & Yes & \\
\hline Ronco et al, 1988, Italy (24) & Yes & \\
\hline Hull et al, 1989 , United States (25) & Yes & \\
\hline Morabia et al, 1992, United States (26) & Yes & \\
\hline $\begin{array}{l}\text { Hansen \& Lauritsen, 1994, Denmark (27) } \\
\text { Jockel et al, 1994, Germany (28) }\end{array}$ & $\begin{array}{l}\text { No } \\
\text { Yes }\end{array}$ & $\begin{array}{l}\text { Case-referent study nested in a cohort included in the European cohort } \\
\text { [Simonato et al, } 1991 \text { (55)] }\end{array}$ \\
\hline \multicolumn{3}{|l|}{ Cohort studies } \\
\hline Dunn \& Weir, 1968 , United States (29) & Yes & \\
\hline Menck \& Henderson, 1976, United States (30) & Yes & \\
\hline Milham, 1976, United States (31) & No & Cohort study updated in [Milham, 1983 (43)] \\
\hline Ott et al, 1976, United States (32) & Yes & \\
\hline \multicolumn{2}{|l|}{ Office of Population Censuses and Surveys, 1978 , } & \\
\hline $\begin{array}{l}\text { United Kingdom (33) } \\
\text { Puntoni et al, 1979, Italy (34) }\end{array}$ & No & Cohort study updated in [Puntoni et al, 1986 (48)] \\
\hline Redmond et al, 1979, United States (35) & Yes & \\
\hline Beaumont \& Weiss, 1980, United States (36) & No & Cohort study updated in [Beaumont \& Weiss, 1981 (39)] \\
\hline Peterson \& Milham, 1980, United States (37) & Yes & 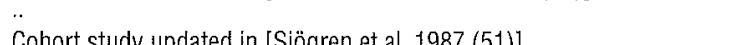 \\
\hline $\begin{array}{l}\text { Sjögren, } 1980 \text {, Sweden (38) } \\
\text { Beaumont \& Weiss, 1981, United States (39) }\end{array}$ & $\begin{array}{l}\text { No } \\
\text { Yes }\end{array}$ & Cohort study updated in [Sjögren et al, 1987 (51)] \\
\hline Polednak 1981, United States (40) & Yes & \\
\hline Sjögren \& Malker, 1982, Sweden (41) & No & Cohort study updated in [Sjögren \& Carstensen, 1986 (50)] \\
\hline McMillan, 1983, United Kingdom (42) & Yes & \\
\hline Milham, 1983 , United States (43) & Yes & \\
\hline Gallagher \& Threlfall, 1983, Canada (44) & Yes & \\
\hline Fletcher \& Ades, 1984, United Kingdom (45) & Yes & \\
\hline Becker et al, 1985 , Germany (46) & No & Cohort study updated in [Becker et al, 1991 (57)] \\
\hline Newhouse et al, 1985, United Kingdom (47) & Yes & \\
\hline Puntoni et al, 1985 , Italy (48) & Yes & \\
\hline Sjögren et al, 1985 , Sweden (49) & Yes & \\
\hline Sjögren \& Carstensen, 1985 , Sweden (50) & No & Cancer incidence study in a cohort also followed up for mortality \\
\hline Sjögren et al, 1987, Sweden (51) & & Cohort included in the European cohort [Simonato et al, 1991 (55)] \\
\hline Tola et al, 1988 , Finland (52) & No & Cohort included in the European cohort [Simonato et al, 1991 (55)] \\
\hline Melkild et al, 1989 , Norway (53) & Yes & \\
\hline Merlo et al, 1989, Italy (54) & Yes & \\
\hline Simonato et al, 1991, Europe (55) & Yes & \\
\hline Steenland et al, 1991, United States (56) & Yes & \\
\hline Becker et al, 1992, Germany (57) & No & Cohort included in the European cohort [Simonato et al, 1991 (55)] \\
\hline Moulin et al, 1993, France (58) & No & Cohort included in the European cohort [Simonato et al, 1991 (55)] \\
\hline Danielsen et al, 1993, Norway (59) & Yes & \\
\hline
\end{tabular}

welders $(12,14)$. Twelve relative risks $(24 \%)$ were higher than 2.00 , most of them (10 RR values) being observed in case-referent studies.

\section{The meta-analysis}

Table 3 shows the results of the meta-analysis for each welding category. The combined relative risks are provided for the population-based, case-referent, and cohort studies separately and combined.

For the "all or unspecified welding categories", the combined relative risks were 1.39 (observed 585, 95\% CI 1.28-1.51) for the 7 population-based studies, 1.72 (observed $230,95 \%$ CI 1.36-2.18) for the 9 case-refer- ent studies, and 1.27 (observed 213,95\% CI 1.10-1.46) for the 3 cohort studies. When the case-referent studies and cohort studies (12 studies) were combined, the relative risk was 1.37 (observed 443, 95\% CI 1.22-1.55). This value was similar to that observed for the population-based studies (RR 1.39). The combination of all studies concerning "all or unspecified welding categories" (19 studies) led to a relative risk of 1.38 (observed $1028,95 \%$ CI $1.29-1.48)$.

For the shipyard welders, the combined relative risks were 1.16 (observed $144,95 \%$ CI $0.92-1.47$ ) for the 6 case-referent studies and 1.36 (observed 161, 95\% CI $1.17-1.60)$ for the 8 cohort studies, the combined rela- 
Table 2. Description of the studies included in the meta-analysis on lung cancer in welders. The studies have been classified by increasing relative risks in each welding or study design category. ( $95 \% \mathrm{Cl}=95 \%$ confidence interval, $\mathrm{OR}=$ odds ratios, $\mathrm{SMR}=$ standardized mortality ratio, SIR = standardized incidence ratio, PMR = proportionate mortality ratio)

\begin{tabular}{|c|c|c|c|}
\hline Welding categories & Observeda & Relative risks & $95 \% \mathrm{Cl}$ \\
\hline \multicolumn{4}{|l|}{ All or unspecified } \\
\hline \multicolumn{4}{|l|}{ Mortality and morbidity statistics } \\
\hline $\begin{array}{l}\text { Peterson \& Milham, 1980, United States (37) } \\
\text { Milne et al, 1983, United States (16) } \\
\text { Milham, 1983, United States (43) } \\
\text { Menck \& Henderson, 1976, United States ( } 30) \\
\text { Gallagher \& Threlfall, 1983, Canada (44) } \\
\text { Office of Population Censures and Surveys, 1978, United Kingdom (33) } \\
\text { Gottlieb, 1980, United States (15) }\end{array}$ & $\begin{array}{r}27 \\
5 \\
177 \\
48 \\
74 \\
246 \\
8\end{array}$ & $\begin{aligned} P M R & =0.99 \\
O R & =1.2 \\
P M R & =1.26 \\
\text { SMR } & =1.37 \\
P M R & =1.45 \\
\text { SMR } & =1.51 \\
O R & =3.5\end{aligned}$ & $\begin{array}{l}0.43-3.59 \\
0.73-16.7 \\
0.66-1.45 \\
1.08-1.47 \\
1.01-1.82 \\
1.15-1.83 \\
1.33-1.71\end{array}$ \\
\hline \multicolumn{4}{|l|}{ Case-referent studies } \\
\hline $\begin{array}{l}\text { Jockel et al, 1994, Germany (28) } \\
\text { Benhamou et al, 1988, France (22) } \\
\text { Morabia et al, 1992, United States (26) } \\
\text { Kjuus et al, 1986, Norway (19) } \\
\text { Gerin et al, 1984, Canada (17) } \\
\text { Buiatti et al, 1985, Italy (18) } \\
\text { Ronco et al, 1988, Italy (24) } \\
\text { Lerchen et al, 1987, United States (21) } \\
\text { Breslow et al, 1954, United States (11) }\end{array}$ & $\begin{array}{r}108 \\
18 \\
18 \\
28 \\
12 \\
7 \\
6 \\
19 \\
14\end{array}$ & $\begin{array}{l}\mathrm{OR}=1.24 \\
\mathrm{OR}=1.42 \\
\mathrm{OR}=1.5 \\
\mathrm{OR}=1.9 \\
\mathrm{OR}=2.4 \\
\mathrm{OR}=2.8 \\
\mathrm{OR}=2.93 \\
\mathrm{OR}=3.2 \\
\mathrm{OR}=7.2\end{array}$ & $\begin{array}{c}0.83-1.86 \\
0.79-2.88 \\
0.8-2.7 \\
0.9-3.7 \\
1.00-5.4 \\
0.9-8.5 \\
0.87-9.82 \\
1.4-7.4 \\
1.9-44.3\end{array}$ \\
\hline \multicolumn{4}{|l|}{ Cohort studies } \\
\hline $\begin{array}{l}\text { Dunn \& Weir, 1968, United States (29) } \\
\text { Simonato et al, 1991, Europe (55) } \\
\text { Sjögren et al, 1986, Sweden (49) }\end{array}$ & $\begin{array}{r}49 \\
116 \\
48\end{array}$ & $\begin{array}{l}\text { SMR }=1.05 \\
\text { SMR }=1.34 \\
\text { SMR }=1.34\end{array}$ & $\begin{array}{l}0.78-1.39 \\
1.10-1.60 \\
0.99-1.78\end{array}$ \\
\hline \multicolumn{4}{|l|}{ Shipyard welding } \\
\hline \multicolumn{4}{|l|}{ Case-referent studies } \\
\hline $\begin{array}{l}\text { Blot et al, 1978, United States (12) } \\
\text { Blot et al, 1980, United States (14) } \\
\text { Rinsky et al, 1988, United States (23) } \\
\text { Schoenberg et al, 1987, United States (20) } \\
\text { Hull et al, 1989, United States (25) } \\
\text { Lerchen et al, 1987, United States (21) }\end{array}$ & $\begin{array}{r}11 \\
11 \\
41 \\
38 \\
37 \\
6\end{array}$ & $\begin{array}{l}O R=0.7 \\
O R=0.9 \\
O R=1.13 \\
O R=1.2 \\
O R=1.7 \\
O R=2.2\end{array}$ & $\begin{array}{c}0.32-1.41 \\
0.4-2.3 \\
0.76-1.68 \\
0.8-1.9 \\
0.9-3.1 \\
0.5-9.1\end{array}$ \\
\hline \multicolumn{4}{|l|}{ Cohort studies } \\
\hline $\begin{array}{l}\text { Mc Millan, 1983, United Kingdom (42) } \\
\text { Newhouse et al, 1986, United Kingdom (47) } \\
\text { Simonato et al, 1991, Europe (55) } \\
\text { Beaumont and Weiss, 1981, United States (39) } \\
\text { Puntoni et al, 1986, Italy (48) } \\
\text { Merlo et al, 1989, Italy (54) } \\
\text { Melkild et al, 1989, Norway (53) } \\
\text { Danielsen et al, 1993, Norway (59) }\end{array}$ & $\begin{array}{r}5 \\
26 \\
36 \\
50 \\
12 \\
16 \\
7 \\
9\end{array}$ & $\begin{aligned} \text { PMR } & =1.04 \\
\text { SMR } & =1.13 \\
\text { SMR } & =1.26 \\
\text { SMR } & =1.32 \\
\text { SMR } & =1.57 \\
\text { SMR } & =1.67 \\
\text { SIR } & =2.21 \\
\text { SIR } & =2.5\end{aligned}$ & $\begin{array}{l}0.34-2.43 \\
0.80-1.57 \\
0.88-1.74 \\
0.98-1.74 \\
0.82-2.76 \\
0.95-2.71 \\
0.88-4.54 \\
1.14-4.75\end{array}$ \\
\hline \multicolumn{4}{|l|}{ Nonshipyard welding } \\
\hline \multicolumn{4}{|l|}{ Case-referent studies } \\
\hline Lerchen et al, 1987, United States (21) & 13 & $O R=3.8$ & $1.4-10.7$ \\
\hline \multicolumn{4}{|l|}{ Cohort studies } \\
\hline $\begin{array}{l}\text { Ott et al, 1976, United States (32) } \\
\text { Steenland et al, 1991, United States (56) } \\
\text { Simonato et al, 1991, Europe (55) } \\
\text { Fletcher \& Ades, 1984, United Kingdom (45) } \\
\text { Polednak, 1981, United States (40) } \\
\text { Redmond et al, 1979, United States (35) }\end{array}$ & $\begin{array}{r}2 \\
39 \\
80 \\
8 \\
17 \\
14\end{array}$ & $\begin{array}{l}\text { SMR }=1.00 \\
\text { SMR }=1.07 \\
\text { SMR }=1.37 \\
\text { SMR }=1.46 \\
\text { SMR }=1.5 \\
\text { SMR }=1.51\end{array}$ & $\begin{array}{l}0.12-3.61 \\
0.76-1.46 \\
1.09-1.71 \\
0.62-2.88 \\
0.87-2.39 \\
0.82-2.53\end{array}$ \\
\hline \multicolumn{4}{|l|}{ Mild steel welding } \\
\hline \multicolumn{4}{|l|}{ Case-referent studies } \\
\hline $\begin{array}{l}\text { Gerin et al, 1984, Canada (17) } \\
\text { Hull et al, 1989, United States (25) }\end{array}$ & 56 & $\begin{array}{l}\mathrm{OR}=1.2 \\
\mathrm{OR}=1.6\end{array}$ & $\begin{array}{l}0.1-9.4 \\
0.8-3.1\end{array}$ \\
\hline \multicolumn{4}{|l|}{ Cohort studies } \\
\hline $\begin{array}{l}\text { Steenland et al, 1991, United States (56) } \\
\text { Simonato et al, 1991, Europe (55) }\end{array}$ & $\begin{array}{l}39 \\
40\end{array}$ & $\begin{array}{l}\text { SMR }=1.07 \\
\text { SMR }=1.78\end{array}$ & $\begin{array}{l}0.76-1.46 \\
1.27-2.43\end{array}$ \\
\hline \multicolumn{4}{|l|}{ Stainless steel welding } \\
\hline \multicolumn{4}{|l|}{ Case-referent studies } \\
\hline $\begin{array}{l}\text { Hull et al, 1989, United States (25) } \\
\text { Gerin et al, 1984, Canada (17) } \\
\text { Kjuus et al, 1986, Norway (19) }\end{array}$ & $\begin{array}{l}61 \\
10 \\
16\end{array}$ & $\begin{array}{l}O R=1.3 \\
O R=3.3 \\
O R=3.3\end{array}$ & $\begin{array}{l}0.6-2.3 \\
1.2-9.2 \\
1.2-9.3\end{array}$ \\
\hline \multicolumn{4}{|l|}{ Cohort studies } \\
\hline $\begin{array}{l}\text { Simonato et al, 1991, Europe (55) } \\
\text { Polednak, 1981, United States (40) }\end{array}$ & 20 & $\begin{array}{l}\text { SMR }=1.23 \\
\text { SMR }=1.24\end{array}$ & $\begin{array}{l}0.75-1.90 \\
0.50-2.55\end{array}$ \\
\hline
\end{tabular}

\footnotetext{
a Observed numbers of lung cancer cases (case-referent studies), lung cancer deaths (mortality studies), lung cancer diagnoses (cancer incidence studies).
} 
Table 3. Results of the meta-analysis on lung cancer in welders. ( $R R=$ relative risks, $95 \% \mathrm{Cl}=95 \%$ confidence interval, $d f=$ degree of freedom)

\begin{tabular}{|c|c|c|c|c|c|}
\hline Welding categories & Number & Heterogeneity & Observeda & Combined RR & $95 \% \mathrm{Cl}$ \\
\hline \multicolumn{6}{|l|}{ All or unspecified } \\
\hline Population-based studies & 7 & $\begin{array}{c}x^{2}=7.63 \\
\mathrm{df}=6 \\
\mathrm{P}<0.30\end{array}$ & 585 & 1.39 & $1.28-1.51$ \\
\hline Case-referent studies & 9 & $\begin{array}{c}\chi^{2}=10.51 \\
d f=8 \\
P<0.30\end{array}$ & 230 & 1.72 & $1.36-2.18$ \\
\hline Cohort studies & 3 & $\begin{array}{c}\chi^{2}=2.11 \\
d f=2 \\
P<0.50\end{array}$ & 213 & 1.27 & $1.10-1.46$ \\
\hline Case-referent and cohort studies & 12 & $\begin{array}{c}\chi^{2}=17.51 \\
d f=11 \\
P<0.10\end{array}$ & 443 & 1.37 & $1.22-1.55$ \\
\hline All studies & 19 & $\begin{array}{c}\chi^{2}=25.17 \\
d f=18 \\
P<0.20\end{array}$ & 1028 & 1.38 & $1.29-1.48$ \\
\hline \multicolumn{6}{|l|}{ Shipyard welding } \\
\hline Case-referent studies & 6 & $\begin{array}{c}\chi^{2}=4.36 \\
d f=5 \\
P<0.50\end{array}$ & 144 & 1.16 & $0.92-1.47$ \\
\hline Cohort studies & 8 & $\begin{array}{c}\chi^{2}=6.63 \\
d f=7 \\
P<0.50\end{array}$ & 161 & 1.36 & $1.17-1.60$ \\
\hline All studies & 14 & $\begin{array}{c}\chi^{2}=12.18 \\
d f=13 \\
P<0.90\end{array}$ & 305 & 1.30 & $1.14-1.48$ \\
\hline \multicolumn{6}{|l|}{ Nonshipyard welding } \\
\hline Case-referent study & 1 & & 13 & 3.8 & $1.4-10.7$ \\
\hline Cohort studies & 6 & $\begin{array}{c}\chi^{2}=2.32 \\
d f=5 \\
P<0.90\end{array}$ & 160 & 1.31 & $1.12-1.54$ \\
\hline All studies & 7 & $\begin{array}{c}\chi^{2}=6.42 \\
d f=6 \\
P<0.50\end{array}$ & 173 & 1.35 & $1.15-1.58$ \\
\hline \multicolumn{6}{|l|}{ Mild steel welding } \\
\hline Case-referent studies & 2 & $\begin{array}{c}\chi^{2}=0.057 \\
d f=1 \\
P<0.90\end{array}$ & 58 & 1.56 & $0.82-2.99$ \\
\hline Cohort studies & 2 & $\begin{array}{c}3.31 \\
d f=1 \\
P<0.10\end{array}$ & 79 & 1.49 & $1.15-1.93$ \\
\hline All studies & 4 & $\begin{array}{c}\chi^{2}=3.38 \\
d f=3 \\
P<0.50\end{array}$ & 137 & 1.50 & $1.18-1.91$ \\
\hline \multicolumn{6}{|l|}{ Stainless steel welding } \\
\hline Case-referent studies & 3 & $\begin{array}{c}\chi^{2}=3.43 \\
d f=2 \\
P<0.20\end{array}$ & 87 & 2.00 & $1.22-3.28$ \\
\hline Cohort studies & 2 & $\begin{array}{c}\chi^{2}=0.0003 \\
d f=1 \\
P<1.00\end{array}$ & 27 & 1.23 & $0.82-1.85$ \\
\hline All studies & 5 & $\begin{array}{c}\chi^{2}=5.67 \\
d f=4 \\
P<0.30\end{array}$ & 114 & 1.50 & $1.10-2.05$ \\
\hline
\end{tabular}

\footnotetext{
a Observed numbers of lung cancer cases (case-referent studies), lung cancer deaths (mortality studies), lung cancer diagnoses (cancer incidence studies).
}

tive risk being 1.30 (observed $305,95 \%$ CI $1.14-1.48$ ) for all studies.

With regard to nonshipyard welders, the combined relative risk could be calculated on the basis of 6 cohort studies, 1.31 (observed 160, 95\% CI 1.12-1.54), and for both the cohort and case-referent studies, 1.35 (ob- served $173,95 \%$ CI $1.15-1.58$ ). The comparison of the combined relative risks obtained for the shipyard and nonshipyard welders showed similar values, 1.30 and 1.35 , respectively.

Studies providing results for mild steel and stainless steel welders were less numerous. Only 2 case-referent 
and 2 cohort studies were available for mild steel welders. The combined relative risks were 1.56 (observed 58 , 95\% CI 0.82-2.99) and 1.49 (observed 79, 95\% CI 1.15-1.93), and 1.50 (observed 137, 95\% CI 1.181.91), respectively, for all the studies combined.

Three case-referent and 2 cohort studies were focused on stainless steel welding, leading to combined relative risks of 2.00 (observed $87,95 \%$ CI $1.22-3.28$ ) and 1.23 (observed $27,95 \%$ CI $0.82-1.85$ ), respectively, and a relative risk of 1.50 (observed $114,95 \%$ CI $1.10-2.05$ ) for all the studies combined.

When the mild steel and stainless steel welders were compared, it appeared from table 3 that the combined relative risks observed for these welding categories were only slightly different: 1.56 versus 2.00 for the casereferent studies, 1.49 versus 1.23 for the cohort studies. Furthermore, the same combined relative risk was observed in each welding category on the basis of all the studies combined (RR 1.50).

With regard to the test for heterogeneity, it is worth noting that no significant heterogeneity was discerned for the studies of any welding or study design category.

\section{Discussion}

\section{Cohort studies versus case-referent studies}

The population-based studies used in this meta-analysis are not real cohort studies. Therefore, they were analyzed separately. However, they provided combined relative risks that were similar to those resulting from the cohort studies (RR 1.39 and 1.27, respectively) (table 3).

The combined relative risks calculated on the basis of case-referent studies seemed to differ from those of cohort studies with regard to levels of risk. The combined relative risks were higher for the case-referent studies than for the cohort studies for "all or unspecified welding categories" (RR 1.72 versus 1.27), nonshipyard welding (RR 3.8 based on 1 study versus 1.31), mild steel welding (RR 1.56 versus 1.49 ), and stainless steel welding (RR 2.00 versus 1.23). This finding could be the result of selection bias due to case-referent studies providing high odds ratios in the literature. The tables of some published papers may give the odds ratios of occupations showing an excess rather than occupations with low odds ratios, in particular in hypothesis-generating studies not specifically designed to address the lung cancer risk of welders $(10,60)$.

However, population-based cohort studies may also be affected by such a positive selection bias since the results of welders may not be given because of small numbers of exposed cases and low standardized mortality ratios. Furthermore, table 2 shows that there are more case-referent studies having relative risks of 1.00 or less than there are cohort studies. These remarks would not seem to argue for a publication bias in case-referent studies. Nevertheless, such a selection bias would not hinder the comparison of combined relative risks between welding categories since this selection bias is likely to have affected all the welding categories.

Regarding the heterogeneity between effect estimates which appeared within the categories of studies (table 3), it may be that the lack of heterogeneity contrasts with the range of relative risks observed in the 9 case-referent studies among "all or unspecified welding categories", from 1.24 to 7.2 with nonoverlapping $95 \%$ confidence intervals ( $0.83-1.86$ and $1.9-44.3$, respectively) (table 2). This occurrence is due to the fact that the studies having the lowest relative risks $(19,22,26,28)$, from 1.24 to 1.9 , had the highest numbers of exposed cases and rather narrow $95 \%$ confidence intervals, whereas studies having the highest relative risks $(11,18,21,24)$, from 2.4 to 7.2 , had smaller numbers of exposed cases and comparatively wide $95 \%$ confidence intervals, especially for the study by Breslow et al, with a relative risk of 7.2 based on 7 exposed cases and 2 exposed referents with a $95 \%$ confidence interval of 1.9 to 44.3 . These studies with wide $95 \%$ confidence intervals are of little effect in calculations of combined relative risks since they have high variances.

\section{Lung cancer risk for "all or unspecified welding categories"}

Several reviews of the literature have been published previously (61-64). All the authors agreed that there is a $30 \%$ to $40 \%$ increase in the relative risk of lung cancer among welders when compared with the general population. The results of the present meta-analysis are consistent with these conclusions, since the combined relative risk of the "all or unspecified" welding category was $1.37(95 \%$ CI $1.22-1.55)$ when the case-referent and cohort studies were combined and 1.38 (1.29-1.48) when the population-based studies were included (table 3).

When the possible selection bias of "positive" casereferent studies was controlled, the estimate of the lung cancer risk of all welding categories was the combined relative risk calculated from the cohort studies (RR 1.27, $95 \%$ CI $1.10-1.46$ ).

\section{Shipyard versus nonshipyard welders}

Asbestos exposure, which is related to lung cancer occurrence (65), may be a confounding factor when the lung cancer risk of welders is assessed. Furthermore, most authors assume that asbestos exposure is more likely to have occurred in shipyards than in other workplaces (1). As a control for this possible confounding factor, shipyard welders were considered separately in the epidemiologic studies. 
The present meta-analysis failed to confirm that shipyard welders were at a higher lung cancer risk than nonshipyard welders since the combined relative risks were similar, $1.30(95 \% \mathrm{CI} 1.14-1.48)$ and $1.35(95 \%$ CI 1.15-1.58), respectively (table 3 ).

\section{Mild steel versus stainless steel welders}

Epidemiologic studies focusing on the lung cancer risk of mild steel welders as compared with that of stainless steel welders were set up in the 1980s, following the first report by Sjögren (38). The objective of these studies was to assess the lung cancer risk due to exposure to hexavalent chromium and nickel when stainless steel welding was compared with mild steel welding.

The present meta-analysis failed to confirm the hypothesis of a higher risk in association with stainless steel, since the combined relative risks were similar when the case-referent studies only (2.00 versus 1.56 , respectively) or the cohort studies only (1.23 versus 1.49 , respectively) or both study designs ( 1.50 in each category) were considered (table 3 ). In addition, the European study showed that the standardized mortality ratio of mild steel welders was statistically significant (SMR $1.78,95 \% \mathrm{CI}$ 1.27-2.43) and higher than that of stainless steel welders (SMR 1.23, 95\% CI 0.75-1.90) (55). The latter did not reach statistical significance.

A meta-analysis of stainless steel welding has been published by Sjögren et al (6), including 3 case-referent studies $(17,19,27)$ and 2 cohort studies $(51,58), 3$ of them being included in the European study $(27,51,58)$. This meta-analysis provided a combined relative risk of 1.94 (95\% CI 1.28-2.93) for welders exposed to stainless steel welding fumes, a finding suggesting a relation between stainless steel welding and the occurrence of lung cancer. This conclusion has been discussed since the authors did not consider studies providing low relative risks for stainless steel welders (8). Moreover, 4 of the studies reviewed by Sjögren et al provided relative risks for mild steel welders $(17,27,51,58)$; the combination of these relative risks leads to a significantly high combined relative risk (RR 1.56, 95\% CI 1.06-2.29), which does not markedly differ from that observed for stainless steel welders by Sjögren et al.

With regard to dose-response relationship, the most relevant data were provided by the European study, which used a specific job-exposure matrix to provide standardized mortality ratios by cumulative exposure to total fumes, hexavalent chromium, and nickel exposure among stainless steel welders $(55,66)$. No dose-response relationship was observed for lung cancer risk with these estimates for various welding fume components, even in the category of predominantly stainless steel welders. With hexavalent chromium as the variable, the standardized mortality ratios were 1.91 (observed 3, 95\% CI $0.39-5.58)$ for a cumulative dose of $<0.5 \mathrm{mg}\left(\right.$ year $\left.\cdot \mathrm{m}^{3}\right)$ versus 1.67 (observed 9, 95\% CI $0.77-3.18$ ) for a cumulative dose of $\geq 0.5 \mathrm{mg}\left(\right.$ year $\left.\cdot \mathrm{m}^{3}\right)$; with nickel as the variable, the standardized mortality ratios were 2.34 (observed 8, 95\% CI 1.01-1.61) for a cumulative dose of $<0.5 \mathrm{mg}\left(\right.$ year $\cdot \mathrm{m}^{3}$ ) versus 1.13 (observed $4,95 \% \mathrm{CI}$ $0.31-2.90$ ) for a cumulative dose of $\geq 0.5 \mathrm{mg}\left(\right.$ year $\cdot \mathrm{m}^{3}$ ). Although some degree of misclassification might have been introduced when the job-exposure matrix was developed, this lack of dose-response relationship with hexavalent chromium exposure is of interest because the statistical power to detect such an association was high (66).

Consequently, it appears that the lung cancer excess of welders cannot be clearly attributed to stainless steel welding.

\section{Healthy worker effect}

The European multicentric study provides results concerning subcohorts of shipyard, nonshipyard, mild steel, and stainless steel welders. The fact that these subcohorts have been included in the same study makes it easier to compare the welding category because differences in the relative risks are unlikely to be due to differences in study design.

With regard to mortality from all causes of death, the standardized mortality ratio observed for mild steel welders was close to that expected in the European study (SMR 1.01, observed 287, 95\% CI 0.90-1.13), whereas a marked healthy worker effect appeared for the stainless steel welders (SMR 0.86, observed 335, 95\% CI 0.770.96 ), the latter being statistically significant. In addition, a strong healthy worker effect was observed in the German cohort of stainless steel welders (SMR 0.79, observed $153,95 \%$ CI $0.67-0.93$ ) (57). These results suggest that the healthy worker effect might have been more marked among stainless steel welders than among mild steel welders. This possibility had been suggested in the literature because stainless steel welders are more qualified and receive higher remuneration than other welders $(7,55)$.

The preceding result raises the question of whether the healthy worker effect could have led to an underestimate of the lung cancer risk of stainless steel welders when compared with mild steel welders. Most studies on the healthy worker effect have demonstrated that it results in low mortality rates mainly for cardiovascular and nonmalignant respiratory diseases and that the healthy worker effect has little influence on the occurrence of cancer, in particular on lung cancer (67). The report by Sterling \& Weinkam (68) disagrees, however, with this conclusion; it suggests that the healthy worker effect is observed for all causes of death, including lung cancer. Consequently, the strong healthy worker effect observed for stainless steel welders may have led to an underestimation of the lung cancer risk of stainless steel welders 
when compared with mild steel welders. Moreover, the degree of underestimation is difficult to assess; therefore we were not able to evaluate the standardized mortality ratio for lung cancer among stainless steel welders in the absence of the healthy worker effect.

\section{Asbestos exposure}

When mortality from pleural mesothelioma was used as an indicator of asbestos exposure, 2 studies among shipyard welders showed high relative risks $(41,42,69)$. However, such excesses were found among nonshipyard welders in 2 Swedish studies $(49,50)$, in the German study of stainless steel welders (57), and in the European study (SMR $>5.00$, observed 5) (55). It is noteworthy that, in the European study, 4 out of the 5 cases of mesothelioma leading to a significant excess occurred in the mild steel and stainless steel subcohorts $(1,55)$.

A French study on the retention of asbestos bodies in the lungs of welders has shown that about $40 \%$ of these workers had asbestos bodies (3). Although this study population was a biased sample of welders with lung disease suspected to be caused by asbestos, it suggests that all welding activities may also involve asbestos exposure.

In summary, it appears that asbestos is likely to be a causative factor for the lung cancer excess observed among welders.

\section{Smoking habits}

Following the reports by Axelson (70), it has been established that a lung cancer excess ranging between 1.30 and 1.50 in a cohort study may be the result of tobacco overconsumption in the study cohort when compared with the general population. The fact that the lung cancer risks of welders range between 1.30 and 1.50 raises the important question of whether these excesses are possibly partly or totally explained by smoking.

When case-referent studies only are considered, it seems unlikely that smoking accounts for the observed lung cancer excesses since most of the odds ratios were adjusted for smoking (17-22, 24, 26-28). However, this assumption may be inaccurate due to the possible selection of "positive" results which may have overestimated the lung cancer risk of welders in published reports.

The design of cohort studies does not allow such an assessment to be made since data on smoking are not available for all workers included in historical cohorts (70). The literature provides arguments suggesting that welders smoke more than the general populations used as external references. The Registrar General supplement for England and Wales showed that the "smoking ratio" of "welders, cutters and braziers", as compared with that of the general male population was 1.22 (33). According to population surveys in the United States, the proportions of smokers among welders as compared with that of the general male population were $52.1 \%$ versus $42.6 \%(71), 45.4 \%$ versus $36.8 \%(72)$, and $42.7 \%$ versus $30.1 \%$ (73). When Axelson's method is applied to these proportions, with the assumption of a relative risk of 10.00 for lung cancer among smokers as compared with nonsmokers, the lung cancer excess due to smoking among welders would be about 1.20 . These estimates are lower than the risk estimates from cohort studies.

Furthermore, smoking was also more prevalent among the welders in the French study, and this prevalence was assumed to lead to a 1.06 excess of lung cancer in a comparison with the nonwelding reference group (58). This value was lower than the relative risk of 1.32 observed between welders and the internal reference group of nonwelders (58). In the American study by Steenland et al (56), smoking overconsumption was detected which would lead to an approximately $10 \%$ excess of lung cancer among welders.

Consequently, the hypothesis that smoking could be responsible for part of the lung cancer excess of welders cannot be discarded.

\section{Concluding remarks}

The results of the meta-analysis are consistent with those of previously published reviews of the literature which concluded that there is a $30 \%$ to $40 \%$ increase in the relative risk of lung cancer among welders when they are compared with the general population.

Similar combined relative risks were observed for shipyard and nonshipyard welders. The meta-analysis failed to demonstrate that stainless steel welders, although potentially exposed to nickel and hexavalent chromium, are at higher lung cancer risk than mild steel welders. This conclusion should be considered in the light of the fact that the standardized mortality ratio for lung cancer among stainless steel welders may have been underestimated by a marked healthy worker effect.

The literature shows that asbestos exposure and smoking may be confounding factors in epidemiologic studies on the lung cancer risk of welders and therefore the combination of their carcinogenic effects may account for part of the lung cancer excess observed.

\section{References}

1. International Agency for Research on Cancer (IARC). Chromium, nickel and welding fumes. Lyon: IARC, 1990. IARC monographs on the evaluation of carcinogenic risks to humans, vol 49

2. Ulfvarson U. Survey of air contaminants from welding. Scand J Work Environ Health 1981;7 supp1 2:1-28

3. Pairon JC, Martinon L, Iwatsubo Y, Vallentin F, Billon-Galland MA, Bignon $J$, et al. Retention of asbestos bodies in the lungs of welders. Am J Ind Med 1994;25:793-804 
4. Langård S. Role of chemical species and exposure characteristics in cancer among persons occupationally exposed to chromium compounds. Scand J Work Environ Health 1993;19 suppl 1:81-9.

5. Langård S. Nickel-related cancer in welders. Sci Total Environ 1994;148:303 9

6. Sjögren B, Hansen KS, Kjuus H, Persson PG. Exposure to stainless steel welding fumes and lung cancer: a meta-analysis. Occup Environ Med 1994;51:335-6.

7. Marini F, Ferré MP, Gross H, Mantout B, Huvinen M, Beaufils D, et al. Does welding stainless steel causes lung cancer? [letter to the editor]. Scand J Work Environ Health $1995 ; 21: 65-6$.

8. Moulin JJ. Assessment of risk of lung cancer among mild steel and stainless steel welders [letter to the editor]. Occup Environ Med 1995;52:284-5.

9. Ahlbom A. Biostatistics for epidemiologists. Boca Raton (FL): Lewis Publishers, 1993.

10. Greenland S. Quantitative methods in the review of epidemiologic literature. Epidemiol Rev 1987;9:1-30

11. Breslow L, Hoaglin L, Rasmussen G, Abrams HK. Occupations and cigarette smoking as factor in lung cancer. Am J Public Health 1954;44:171 - 81 .

12. Blot WJ, Harrington JM, Toledo A, Hoover R, Heath CW, Fraumeni JF, Lung cancer after employment in shipyards during World War II. N Engl J Med 1978;299:620—4.

13. Decouflé P, Stanislawczyk K, Houten L, Bross J, Viadana E. Retrospective survey of cancer in relation to occupation. Cincinnati $(\mathrm{OH})$ : National Institute for Occupational Health and Safety, 1978. NIOSH publication no 77-178.

14. Blot WJ, Morris LE, Stroube R, Tagnon I, Fraumeni JF. Lung and laryngeal cancers in relation to shipyard employment in Coastal Virginia. JNCI 1980;65:571-5.

15. Gottlieb M S. Lung cancer and the petroleum industry in Louisiana. J Occup Med 1980;22:384-8.

16. Milne K, Sandler D P, Everson R B, Brown S M. Lung cancer and occupation in Alameda county: a death certificate casecontrol study. Am J Ind Med 1983;4:565-75.

17. Gerin M, Siemiatycki G, Richardson L, Pellerin J, Lakhani R, Dewar R. Nickel and cancer associations from a multicancer occupation exposure case-referent study: preliminary findings. In: Sunderman FW, editor. Nickel in the Human Environment. Lyon: International Agency for Research on Cancer (IARC), 1984:105-15. Scientific publication no 53.

18. Buiatti E, Kriebel D, Geddes M, Santucci M, Pucci N. A case control study of lung cancer in Florence, Italy; I occupational risk factors. J Epidemiol Community Health 1985;39:24450 .

19. Kjuus H, Skjerven R, Langård S, Lien JT, Aamodt T. A casereferent study of lung cancer, occupational exposures and smoking: I comparison of title-based and exposure-based occupational information. Scand J Work Environ Health 1986; $12: 193-202$

20. Schoenberg JB, Stemhagen A, Mason TJ, Patterson J, Bill J, Altman R. Occupation and lung cancer risk among New Jersey white males. JNCI 1987;79:13-21.

21. Lerchen ML, Wiggins CL, Samet JM. Lung cancer and occupation in New Mexico. JNCI 1987;79:639-45.

22. Benhamou $S$, Benhamou E, Flamant R. Occupational risk factors of lung cancer in a French case-control study. Br J Ind Med 1988;45:231-3.

23. Rinsky RA, Melius JM, Hornung RW, Zumwalde RD, Waxweiler RJ, Landrigan J, et al. Case-control study of lung cancer in civilian employees at the Portsmouth naval shipyard,
Kittery, Maine. Am J Epidemiol 1988;127:55-64.

24. Ronco G, Ciccione G, Mirabelli D, Troia B, Vineis P. Occupation and lung cancer in two industrialized areas of northern Italy. Int J Cancer 1988;41:354-8.

25. Hull CJ, Doyle E, Peters JM, Garabrant DH, Bernstein L, Preston-Martin S. Case-control study of lung cancer in Los Angeles county welders. Am J Ind Med 1989;16:103-12.

26. Morabia A, Markowitz S, Garibaldi K, Wynder E L. Lung cancer and occupation: results of a multicentre case-control study. Br J Ind Med 1992;49:721-7.

27. Hansen KS, Lauritsen J. A nested case-control study of lung cancer in welders and other metal workers. Presented at the 9th international symposium on epidemiology in occupational health; September of 1992 in Cincinnati $(\mathrm{OH})$.

28. Jockel KH, Aahrens W, Bolm-Audorff U. Lung cancer risk and welding: preliminary results from an ongoing case-control study. Am J Ind Med 1994;25:805-12.

29. Dunn JE, Weir JM. A prospective study of mortality of several occupational groups: special emphasis on lung cancer. Arch Environ Health 1968; 17:71-6.

30. Menck HR, Henderson BE. Occupational differences in rates of lung cancer. J Occup Med 1976;18:797-801.

31. Milham $\mathrm{S}$. Cancer mortality patterns associated with exposure to metals. Ann NY Acad Sci 1976;271:243-9.

32. Ott MG, Holder BB, Langner RR. Determinants of mortality in an industrial population. J Occup Med 1976;18:171-7.

33. Office of Population Censuses and Surveys. Occupational mortality, 1970-1972: England and Wales. London: Her Majesty's Stationery Office, 1978. Decennial supplement.

34. Puntoni R, Vercelli M, Merlo F, Valerio F, Santi L. Mortality among shipyard workers in Genoa, Italy. Ann NY Acad Sci 1979;330:353-77.

35. Redmond CK, Wieand HS, Rockette HE, Sass R, Weinberg G. Long term mortality experience of steel workers: update for NIOSH contract. Cincinnati $(\mathrm{OH})$ : National Indstitute for Occupational Safety and Health (NIOSH), 1979. No HSM $99-71-32$.

36. Beaumont BJ, Weiss NS. Mortality of welders, shipfitters, and other metal trades workers in boilermakers local no 104, AFLCIO. Am J Epidemiol 1980;112:775-86.

37. Peterson GR, Milham JS. Occupational mortality in the state of California 1969-1971. Cincinnati (OH): National Institute for Occupational Safety and Health (NIOSH), 1980. NIOSH publication no 80104

38. Sjögren B. A retrospective cohort study of mortality among stainless steel welders. Scand J Work Environ Health 1980;6: $197-200$.

39. Beaumont JJ, Weiss NS. Lung cancer among welders. J Occup Med 1981;23:839_44.

40. Polednak AP. Mortality among welders, including a group exposed to nickel oxides. Arch Environ Health 1981;36:235 42.

41. Sjögren B, Malker H. Chromium and asbestos as two probable risk factors in lung cancer among welders. J Occup Med 1982; $24: 874-5$.

42. McMillan GHG, Pethybridge RJ. The health of welders in Naval dockyards: proportional mortality study of welders and two control groups. J Soc Occup Med 1983;33:75 - 84

43. Milham SJ. Occupational mortality in Washington State 1950-1974. Cincinnati (OH): National Institute for Occupational Safety and Health, 1983. NIOSH publication no 83116.

44. Gallagher RP. Cancer mortality in metal workers. Can Med Assoc J 1983;129:1191-4. 
45. Fletcher AC, Ades A. Lung cancer mortality in a cohort of English foundry workers. Scand J Work Environ Health 1984; 10:7-16.

46. Becker N, Claude J, Frentzel-Beyme R. Cancer risk of arc welders exposed to fumes containing chromium and nickel. Scand J Work Environ Health 1985;11:75-82.

47. Newhouse ML, Oakes D, Woolley AJ. Mortality of weIders and other craftsmen at a shipyard in $\mathrm{NE}$ England. $\mathrm{Br} \mathrm{J}$ Ind Med 1985;42:406-10.

48. Puntoni R, Vercelli M, Di Giorgio F, Valerio F, Bonassi S, Ceppi $\mathrm{M}$, et al. Mortality study among autogenous and electrical welders in the port of Genoa (Italy). In: Stern RM, Berlin A, Fletcher AC, Jarvisalo J, editors. Proceedings of the international conference on health hazards and biological effects of welding fumes and gases; February 1985, Amsterdam. Amsterdam: Excerpta Medica, 1986;469-72.

49. Sjögren B, Weiner J, Horte LG, Carstensen J. Mortality among Swedish welders and gas-cutters. In: Stern RM, Berlin A, Fletcher AC, Jarvisalo J, editors. Proceedings of the international conference on health hazards and biological effects of welding fumes and gases; February 1985; Amsterdam. Amsterdam: Excerpta Medica, 1986;457-9.

50. Sjögren B, Carstensen J. Cancer morbidity among Swedish welders and gas cutters. In: Stern RM, Berlin A, Fletcher AC, Järvisalo $\mathrm{J}$, editors. Proceedings of the international conference on health hazards and biological effects of welding fumes and gases; February 1985; Amsterdam. Amsterdam; Excerpta Medica, 1986;461-3.

51. Sjögren B, Gustavsson A, Hedström L. Mortality in two cohorts of welders exposed to high-and low-levels of hexavalent chromium. Scand J Work Environ Health 1987;13:247-51.

52. Tola S, Kalliomäki PL, Pukkala E, Asp S, Korkala ML. Incidence of cancer among welders, platers, machinists, and pipe fitters in shipyards and machine shops. Br J Ind Med 1988;45: 209-18.

53. Melkild A, Langård S, Andersen A, Stray Tønnessen JN. Incidence of cancer among welders and other workers in a Norwegian shipyard. Scand J Work Environ Health 1989;15: $387-94$

54. Merlo F, Costantini M, Doria M. Cause specific mortality among workers exposed to welding fumes and gases: a historical prospective study. J Univ Occup Environ Health 1989;11 suppl:302-15.

55. Simonato L, Fletcher AC, Andersen A, Anderson K, Becker $\mathrm{N}$, Chang-Claude J, et al. An historical prospective study of European stainless steel, mild steel and shipyard welders. Br J Ind Med 1991;48:145 54.

56. Steenland K, Beaumont J, Eliot L. Lung cancer in mild steel welders. Am J Epidemiol 1991;133:220—9.

57. Becker N, Chang-Claude J, Frentzel-Beyme R. Risk of cancer for arc welders in the Federal Republic of Germany: results of a second follow up (1983-8). Br J Ind Med 1991;48:67583.

58. Moulin JJ, Wild P, Haguenoer JM, Faucon D, de Gaudmaris
R, Mur JM, et al. A mortality study among mild steel and stainless steel welders. Br J Ind Med 1993;50:234 - 43.

59. Danielsen E, Langard S, Andersen A, Knudsen O. Incidence of cancer among welders of mild steel and other shipyard workers. Br J Ind Med 1993;50:1097-103.

60. Boffetta P, Fu H. Cancer and occupational exposure to inorganic lead compounds: a meta-analysis of published data. Occup Environ Med 1995;52:73-81

61. Stern RM. Assessment of risk of lung cancer for welders. Arch Environ Health 1983:38:148-55.

62. Peto J. Cancer morbidity and mortality studies of welders. In: Stern RM, Berlin A, Fletcher AC, Järvisalo J, editors. Proceedings of the international conference on health hazards and biological effects of welding fumes and gases; February 1985; Amsterdam. Amsterdam: Excerpta Medica, 1986;423-34.

63 Moulin JJ, Diebold F, Limasset J C. Risque de cancer chez les soudeurs: revue bibliographique des enquêtes épidemiologiques. Cahe Notes Doc INRS 1991;145:679-91.

64. Langård S, Stern RM. Nickel in welding fumes :a cancer hazard to welders? a review of epidemiologic studies on cancer in welders. In: Sunderman FW, editor. Nickel in the human environment. Lyon: International Agency for Research on Cancer, 1984:95-103. Scientific publication no 53.

65. International Agency for Research on Cancer (IARC). Overall evaluations of carcinogenicity: an updating of IARC monographs volumes 1-42. Lyon: IARC, 1987. IARC monographs on the evaluation of carcinogenic risks to humans, suppl 7.

66. Gerin M, Fletcher AC, Gray C, Winkelman R, Boffetta P, Simonato L. Development and use of a welding process exposure matrix in a historical prospective study of lung cancer risk in European welders. Int J Epidemiol 1993;22 suppl 2: $\mathrm{S} 22-\mathrm{S} 27$.

67. Choi BCK. Definition, sources, magnitude, effect modifiers, and strategies of reduction of the healthy worker effect. $J$ Occup Med 1992;34:979-88.

68. Sterling TD, Weinkam JJ. Extent, persistence, and constancy of the healthy worker or healthy person effect by all and selected causes of death. J Occup Med 1986;28:348--53.

69. Sheers G, Coles RM. Mesothelioma risks in a naval dockyard. Arch Environ Health 1980;35:276-82.

70. Axelson O, Steenland K. Indirect methods of assessing the effects of tobacco use in occupational studies. Am J Ind Med 1988;13:105-18.

71. Sterling TD, Weinkam JJ. Smoking characteristics by type of employment. J Occup Med 1976;18:743-54.

72. Brackbill R, Frazier T, Shilling S. Smoking characteristics of US workers, 1978-1980. Am J Ind Med 1988;13:5-41.

73. Nelson DE, Emont SL, Brackbill R, Lorraine L, Peddicord J, Fiore MC. Cigarette smoking prevalence by occupation in the United States: a comparison between 1978 to 1980 and 1987 to 1990. J Occup Med 1994;36:516-25.

Received for publication: 14 May 1996 